\title{
A SUCCESS STORY: EARLY DETECTION OF EXOTIC ANTS
}

\author{
G.M. BURNIP ${ }^{1}$, M. SARTY' ${ }^{2}$ D. GUNAWARDANA ${ }^{3}$ and O. GREEN ${ }^{3}$ \\ ${ }^{1}$ Ministry of Agriculture and Forestry, Biosecurity NZ, PO Box 24, Lincoln \\ ${ }^{2}$ Ministry of Agriculture and Forestry, Biosecurity NZ, PO Box 2526, Wellington \\ ${ }^{3}$ Ministry of Agriculture and Forestry, Biosecurity NZ, PO Box 2095, Auckland
}

Corresponding author: Graham.Burnip@maf.govt.nz

\begin{abstract}
Unwanted exotic ants are routinely detected at New Zealand's borders, carrying the risk of permanent establishment here. Biosecurity New Zealand (BNZ) determined these detections were sufficiently common at some sites to justify routine surveillance. The National Invasive Ant Surveillance (NIAS) programme was initiated to address this issue, and has been operational for five summer seasons. A total of 18 risk sites was surveyed during 2005-06, resulting in 19 exotic ant incursions detected and eradicated. During 2006-07, 98 sites were surveyed, with 11 detections and subsequent eradications. This reduction is very encouraging, and BNZ is hopeful next season's NIAS will continue this trend of reduced exotic ant detections. This favourable reduction likely results from a combination of recent BNZ initiatives, both at the border and pre-border, to reduce the risk of exotic ants entering New Zealand. These include targeting ants in prophylactic toxic baiting programmes at high risk sites (e.g. Auckland and Napier seaports) and initiating ant hygiene programmes for sea containers at several Pacific Island seaports that have previously been identified as the source of many exotic ant incursions.
\end{abstract}

\section{POST-BORDER DETECTIONS OF LYCTUS SPECIES (COLEOPTERA: BOSTRICHIDAE) SINCE 2002}

\author{
K.L. PAICE ${ }^{1}$, D. GUNAWARDANA ${ }^{1}$, M.S. BULLIANS ${ }^{1}$ and D. VOICE ${ }^{2}$ \\ ${ }^{1}$ Ministry of Agriculture and Forestry, PO Box 2095, Auckland, New Zealand \\ ${ }^{2}$ Ministry of Agriculture and Forestry, PO Box 24, Lincoln, New Zealand
}

Corresponding author: kerry.paice@maf.govt.nz.

Since 2002, the MAF Investigation and Diagnostic Centres (IDC) have identified 41 post-border detections of Lyctus species on various items including wood, cane-ware and dried liquorice tea. The annual number of detections has remained constant over the past 5 years. The majority of Lyctus post-borders were identified as the established species, Lyctus brunneus (29), four were identified as Lyctus africanus and one as Lyctus planicollis. Seven Lyctus post-borders were unidentified to species level, although five were keyed out as Lyctus near chilensis. Lyctus species were identified as originating from sixteen countries, with the majority originating from countries within the Asian (16), Oceanian (7) and North American (6) geographic regions. Most Lyctus species are attracted to, and are capable of completing their life cycles in the sapwood of seasoned hardwood timber with a moisture content between 8 and 30\%. Therefore, the length of time and storage environment of susceptible timber between treatment and export are important factors in preventing infestation. Lyctus sp. eggs, deposited in timber pores, are unlikely to be detected during inspection at the New Zealand border. Two case studies are presented. 